\title{
Perancangan dan Realisasi Antena Mikrostrip Fraktal Köch untuk Aplikasi TV Digital di Dalam Ruangan
}

\author{
IRSANDI ANGGELINA, TRASMA YUNITA, LEVY OLIVIA NUR
}

\author{
Fakultas Teknik Elektro Universitas Telkom, Indonesia \\ Email: anggelinairsandinden@student.telkomuniversity.ac.id
}

Received 24 Juli 2019 | Revised 18 Agustus 2019 | Accepted 31 Agustus 2019

\begin{abstract}
ABSTRAK
Siaran TV digital umumnya menggunakan antena tipe Yagi dan Kubikal yang berukuran besar sehingga tidak fleksibel digunakan di dalam ruangan. Penelitian ini merancang dan merealisasikan antena mikrostrip miniaturisasi fraktal Köch agar dimensi antena lebih kecil dan bandwidth lebih besar sehingga cocok digunakan di dalam ruangan. Miniaturisasi antena berupa fraktal Köch iterasi-1 pada patch dan teknik slot iterasi-2 pada ground plane menggunakan pencatuan mikrostrip proximity coupled feed pada alokasi frekuensi TV digital Indonesia 478 - $694 \mathrm{MHz}$ dengan bandwidth 216 MHz. Antena dirancang pada software perancang antena, direalisasikan, diukur, dan diaplikasikan pada TV digital. Hasil simulasi antena menunjukkan bandwidth yang lebih besar dari spesifikasi yaitu 245,99 $\mathrm{MHz}$ pada rentang frekuensi 477,81 - 723,8 $\mathrm{MHz}$. Return loss dan gain untuk direalisasikan sebesar -16,67 dB dan 3,085 dB pada frekuensi tengah 586 $\mathrm{MHz}$. Pola radiasi berbentuk bidirectional dan polarisasi berbentuk linier. Panjang dan lebar antena hasil realisasi $17,33 \mathrm{~cm} \times 17,33 \mathrm{~cm}$.
\end{abstract}

Kata Kunci: TV digital, antena, mikrostrip, Fraktal, Köch

\begin{abstract}
ABSTRAC
Digital TV broadcasting generally uses large Yagi and Cubical type antennas, so it is not flexible to be used indoor. This study designs and applies miniaturization of Köch fractal microstrip antennas to obtain smaller dimensions and larger bandwidth. The miniaturization of antenna are Köch fractal iteration-1 on patch and iteration-2 slot technique on ground plane using proximity coupled feed at frequency allocation $478-694 \mathrm{MHz}$ and the bandwidth is $216 \mathrm{MHz}$. The antenna was designed in software and developed, measured, and applied to digital TV. Antenna simulation results show a greater bandwidth than specification, 245.99 $\mathrm{MHz}$, at the frequency range of 477.81 - 723.8 MHz. Return loss and gain simulation results that meet the specifications to be applied to digital TV antennas are -16.67 and $3.085 \mathrm{~dB}$ at $586 \mathrm{MHz}$ center frequency. The radiation pattern is bidirectional and polarization is linear. The length and width dimensions of the antenna is $17.33 \mathrm{~cm} \times 17.33 \mathrm{~cm}$.
\end{abstract}

Keywords: TV digital, antenna, microstrip, Fractal, Köch

$$
\text { ELKOMIKA - } 16
$$


Anggelina, dkk

\section{PENDAhUluan}

Penyiaran televisi mengalami perkembangan menjadi sistem penyiaran digital yang prinsip kerjanya menggunakan modulasi digital dan sistem kompresi dalam menyiarkan sinyal video, audio, dan data ke pesawat televisi. Selain adanya perkembangan teknologi tentang pemrosesan sinyal digital, penggunaan penyiaran televisi digital menghasilkan gambar dan suara yang lebih tajam dan lebih baik (Gultom, 2018). Hal ini juga dilatarbelakangi oleh kompetisi dengan sistem penyiaran satelit dan kabel sehingga penggunaan siaran televisi analog sudah jarang digunakan karena akan menghemat penggunaan spektrum frekuensi radio. Standar perkembangan teknologi ini memerlukan perangkat yang mendukung fungsi sistem televisi digital. Kinerja sistem ditentukan oleh pemilihan antena yang tepat, efisien dan perancangan yang baik.

Pada umumnya antena televisi menggunakan antena tipe yagi dan kubikal (Candra, 2013). Penggunaan antena tipe yagi memiliki kekurangan berupa dimensi dan ukuran yang besar dan tebal, kurang lebih 1 meter, sehingga hanya bisa digunakan di luar ruangan. Kondisi ini juga memiliki efek buruk pada antena berupa gangguan akibat cuaca buruk seperti hujan dan keadaan lainnya. Selain itu, pada penggunaan antena kubikal yaitu jenis antena kawat untuk penerima televisi digital dengan panjang sekitar $85 \mathrm{~cm}$ masih cenderung besar dan kurang optimal sehingga dibutuhkan suatu antena yang mempunyai dimensi yang kompak. Maka perlu adanya perangkat antena yang mendukung penggunaan televisi digital yang efisien, ekonomis, mudah pembuatannya, serta ergonomis (aman, nyaman, dan fleksibel). Antena tersebut adalah antena mikrostrip yang tersusun atas bagian lapisan tipis konduktor dengan bahan metal dan logam diatas substrat yang mampu merambatkan gelombang elektromagnetik. Antena mikrostrip dapat menghasilkan prototipe performasi antena yang baik serta bentuk dan ukuran dimensi yang lebih kecil, ringan, tipis dan dinamis dari bentuk antena yagi dan kubikal yang memungkinkan penggunaan antena di dalam ruangan. Selain itu, harga produksi yang lebih murah dan memberikan kinerja yang cukup baik.

Dimensi antena yang biasa digunakan yang berukuran besar dan tidak fleksibel digunakan di dalam ruangan melatarbelakangi penggunaan miniaturisasi fraktal Köch pada antena mikrostrip sebagai penangkap siaran televisi digital. Miniaturisasi fraktal Köch bertujuan agar antena lebih fleksibel dan berukuran lebih kecil sehingga dapat memperkecil dimensi antena. Perancangan dan realisasi dilakukan dengan menggunakan patch berupa fraktal Köch iterasi1 dengan bahan substrat FR-4 poxy) dan ground plane berupa iterasi ke-2 fraktal Köch. Jenis sustrat FR-4 (epoxy) digunakan karena memiliki ketebalan yang cukup kecil, mudah didapatkan serta ekonomis. Perancangan antena mikrostrip menggunakan software perancang antena yang bekerja pada rentang frekuensi siaran televisi digital berdasarkan ketetapan peraturan Menteri Komunikasi dan Informatika pada frekuensi $478-694 \mathrm{MHz}$ (Menkominfo, 2011). Pemilihan antena yang tepat yang bekerja pada rentang frekuensi ini akan menjamin kinerja (performansi) sistem tersebut. Karena setiap aplikasi memerlukan suatu karakteristik dari antena yang dipakainya, yang didapatkan pada proses perencanaan dan perancangan antena (Alaydrus, 2011).

Sehingga penulis merasa penelitian ini perlu dilakukan untuk melihat kelayakan serta analisa penggunaan antena mirostrip dengan miniaturisasi fraktal Köch pada televisi digital sehingga menghasilkan suatu desain antena dengan dimensi yang berukuran kecil dan fleksibel digunakan di dalam ruangan. 


\section{$1.1 \quad$ Televisi Digital}

Televisi digital merupakan siaran TV digital yang menyiarkan sinyal video, audio, dan data ke pesawat satelit dengan menggunakan modulasi digital. Jika dibandingkan dengan televisi analog, televisi digital memiliki kualitas penerimaan yang baik, kebutuhan daya pancar yang lebih kecil, ketahanan terhadap interferensi dan kondisi lintasan yang berubah-ubah terhadap waktu serta penggunaan bandwidth yang efisien. Perkembangan dari penyiaran analog ke digital dilakukan dengan dengan mengubah informasi menjadi sinyal digital yang berbentuk bit data pada komputer (Denny, 2010).

Penyiaran TV digital menggunakan frekuensi radio VHF/ UHF sama halnya dengan televisi analog, tetapi bedanya menggunakan format konten yang digital. Pada penyiaran TV digital meskipun semakin jauh dari stasiun pemancar, keadaan sinyal yang diterima akan tetap bagus sehingga mendukung penggunaan antena mikrostrip fraktal Köch pada TV digital yang dirancang di dalam ruangan agar tetap menghasilkan kualitas gambar yang jernih.

\subsection{Frekuensi Penyiaran Digital}

Penyiaran TV digital telah dikembangkan dari Digital Video Broadcasting-Terestrial (DVB-T) menjadi Digital Video Broadcasting-Terestrial second generation (DVB-T2). DVB adalah standar terbuka yang diterima secara international untuk televisi digital yang mendistribusikan data menggunakan dengan berbagai pendekatan yaitu satelit (DVB-S), kabel (DVB-C), terestrial (DVB-T), dan TV Terestrial.

Berdasarkan pada Peraturan Menteri Komunikasi dan Informasi No. 05/PER/M.KOMINFO/2/2012 tentang Standar Penyiaran Televisi Digital Terestrial Penerimaan Tetap Tidak Berbayar (Menkominfo, 2012), isinya menyatakan bahwa standar penyiaran TV digital terestrial free-to-air di Indonesia adalah DVB-T2. Menteri Komunikasi dan Informatika Republik Indonesia nomor 23/PER/M.KOMINFO/11/2011 menetapkan Peraturan Menteri Komunikasi dan Informatika tentang rencana induk (master plan) frekuensi radio untuk keperluan televisi siaran digital terestrial pada pita frekuensi radio $478-694 \mathrm{MHz}$ (Menkominfo, 2011). Berdasarkan tersebut, frekuensi yang digunakan televisi digital pada frekuensi UHF (Wahyu, Syakirotunnikmah, \& Wijanto, 2015) yaitu mulai dari nomor kanal 22 sampai kanal 48 pada Tabel 1.

Ultra High Frequency merupakan gelombang elektromagnetik dengan frekuensi antara 300 $\mathrm{MHz}$ sampai $3 \mathrm{GHz}$ dengan panjang gelombang dari satu sampai 10 desimeter atau berkisar $10 \mathrm{~cm}$ sampai $1 \mathrm{~m}$. Pita frekuensi UHF yang digunakan untuk penyiaran televisi yaitu 470 $806 \mathrm{MHz}$.

\subsection{Fraktal Köch Antena}

Fraktal Köch merupakan salah satu miniaturisasi antena berbentuk kurva segitiga (Nugroho, 2014) dengan penambahan segitiga-segitiga pada sisi yang persisi dengan ukuran kecil sesuai sifat fraktal. Fraktal Köch bertujuan memperkecil dimensi antena sehingga fleksibel digunakan di dalam ruangan. Panjang iterasi- $n$ kurva Köch dihitung berdasarkan Persamaan (1).

$$
L_{n}=L_{0}\left(\frac{4}{3}\right)^{n}
$$


Tabel 1. Spesifikasi Kanal TV UHF

\begin{tabular}{|c|c|c|c|c|c|}
\hline Band & Kanal & Batas Frekuensi (MHz) & Band & Kanal & Batas Frekuensi (MHz) \\
\hline \multirow[t]{21}{*}{ UHF } & 21 & $470-478$ & \multirow[t]{21}{*}{ UHF } & 42 & $638-646$ \\
\hline & 22 & $478-486$ & & 43 & $646-654$ \\
\hline & 23 & $486-494$ & & 44 & $654-662$ \\
\hline & 24 & $494-502$ & & 45 & $662-670$ \\
\hline & 25 & $502-510$ & & 46 & $670-678$ \\
\hline & 26 & $510-518$ & & 47 & $678-686$ \\
\hline & 27 & $518-526$ & & 48 & $686-694$ \\
\hline & 28 & $526-534$ & & 49 & $694-702$ \\
\hline & 29 & $534-542$ & & 50 & $702-710$ \\
\hline & 30 & $542-550$ & & 51 & $710-718$ \\
\hline & 31 & $550-558$ & & 52 & $718-726$ \\
\hline & 32 & $558-566$ & & 53 & $726-734$ \\
\hline & 33 & $566-574$ & & 54 & $734-742$ \\
\hline & 34 & $574-582$ & & 55 & $742-750$ \\
\hline & 35 & $582-590$ & & 56 & $750-758$ \\
\hline & 36 & $590-598$ & & 57 & $758-766$ \\
\hline & 37 & $598-606$ & & 58 & $766-774$ \\
\hline & 38 & $606-614$ & & 59 & $774-782$ \\
\hline & 39 & $614-622$ & & 60 & $782-790$ \\
\hline & 40 & $622-630$ & & 61 & $790-798$ \\
\hline & 41 & $630-638$ & & 62 & $798-806$ \\
\hline
\end{tabular}

Berdasarkan rumus, $L_{0}$ adalah panjang mula-mula, $L_{n}$ adalah panjang setelah iterasi $n$, dan $n$ adalah iterasi ke- $n$. Rumus iterasi tersebut menghasilkan dimensi fraktal dengan bentuk segitiga segmen ke-0 sampai ke- $n$ untuk membentuk suatu dimensi Köch. Adapun rincian tahap iterasi tersebut adalah :

a. Iterasi ke nol (0) digunakan untuk menentukan panjang mula-mula segitiga dengan menggunakan Persamaan (2) (Ismahayati, Soh, Hadibah, \& Vandenbosch, 2011).

$$
\lambda=\frac{c}{f}
$$

Dimana $\lambda$ adalah panjang gelombang $[\mathrm{m}], c$ adalah cepat rambat medium $\left(3 \times 10^{8}\right)$ $\left(\mathrm{m} / \mathrm{s}^{2}\right), f$ adalah frekuensi resonansi [GHz]. Setelah didapatkan panjang gelombang, untuk mendapatkan panjang mula-mula dilakukan subtitusi nilai panjang gelombang pada Persamaan (3) berikut.

$$
L_{0}=\frac{\lambda}{4}
$$

$L_{0}$ adalah panjang mula-mula [m], dan $\lambda$ adalah panjang gelombang [m].

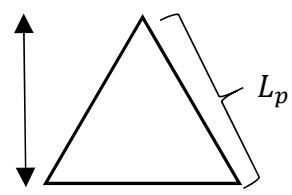

$$
L_{0}=L_{p}\left(\frac{4}{3}\right)^{0}
$$

b. Pada iterasi pertama, segitiga dibagai menjadi tiga bagian dengan ukuran yang sama panjang. Pembagian tersebut merupakan pembagian dari panjang sisi mula-mula $\left(L_{0}\right)$. 


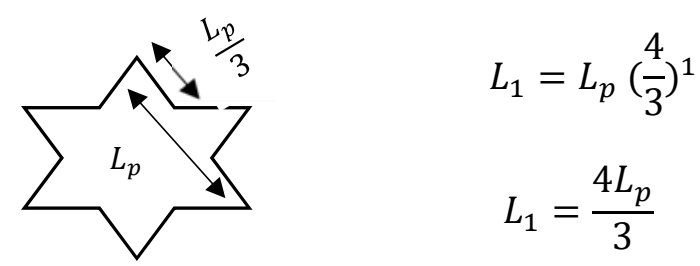

c. Pada iterasi kedua atau iterasi seterusnya, segitiga akan membagi menjadi tiga bagian dengan ukuran yang sama panjang sampai iterasi ke- $n$ atau tak hingga yang disebut Köch snowflake.

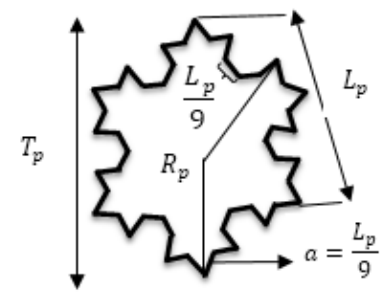

$$
\begin{aligned}
& L_{2}=L_{p}\left(\frac{4}{3}\right)^{2} \\
& L_{2}=\frac{16 L_{p}}{9}
\end{aligned}
$$

Pada setiap iterasi akan mempengaruh dimensi antena, gain, return loss dan daya terima dari antenna dimana ukuran fraktal yang meningkat akan menghasilkan luasan fraktal yang lebih tinggi dan struktur fraktal mampu digunakan untuk antena yang lebih kecil, ringan, dan sederhana. Selain itu, kebutuhan TV digital pada frekuensi rendah sehingga digunakan fraktal Köch iterasi-2 dengan sedikit modifikasi agar memiliki bandwidth yang lebar dan ukuran antena lebih kecil.

\section{PERANCANGAN SISTEM}

\subsection{Diagram Alur Sistem}

Langkah-langkah yang dilakukan dalam perancangan antena mengikuti diagram alir pada Gambar 1. Penelitian ini dimulai dari penentuan spesifikasi antena mikrostrip berdasarkan penelitian sebelumnya untuk televisi digital. Setelah itu dilakukan penentuan bahan substrat, patch, dan ground plane yang akan digunakan, antena akan dirancang pada rentang frekuensi yang ditentukan yaitu $478-694 \mathrm{MHz}$. Tahap pertama dilakukan perancangan fraktal Köch iterasi-1 pada patch dan teknik slot fraktal Köch iterasi-2 pada ground plane antena mikrostrip berdasarkan spesifikasi yang didapat sebelumnya. Perancangan dilakukan pada software perancang antena dan dilakukan optimasi. Hasil simulasi kemudian direalisasikan dan dilakukan pengukuran pada parameter luar berupa pola radiasi, polarisasi, dan gain, dan parameter dalam antena berupa return loss menggunakan NA. Tahap selanjutnya dilakukan analisis terhadap antena hasil simulasi dengan antena hasil pengukuran. Antena kemudian diaplikasikan pada televisi digital untuk melihat hasil perfomansi antena mikrostrip fraktal Köch pada rentang frekuensi siaran televisi digital. 


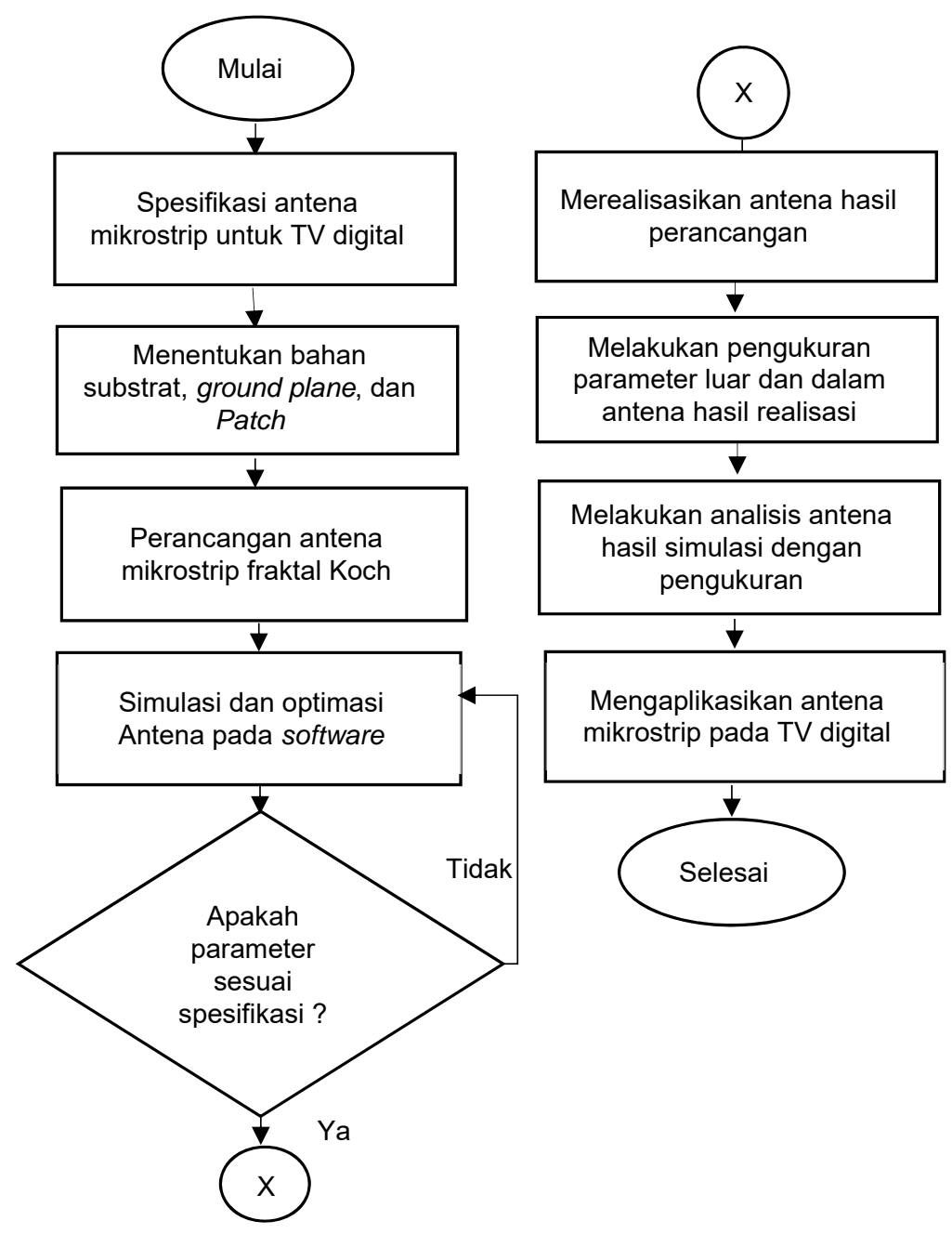

\section{Gambar 1. Diagram Alur Model Sistem}

\subsection{Spesifikasi Televisi Digital}

Pada penelitian ini akan dirancang antena mikrostrip fraktal Köch pada televisi digital dengan spesifikasi seperti pada Tabel 2.

Tabel 2. Spesifikasi Antena Mikrostrip

\begin{tabular}{|c|c|}
\hline Parameter & Spesifikasi \\
\hline Frekuensi Televisi Digital & UHF $(478-694 \mathrm{MHz})$ \\
\hline Frekuensi Tengah & $586 \mathrm{MHz}$ \\
\hline Bandwidth & $216 \mathrm{MHz}$ \\
\hline Polarisasi & Linier \\
\hline Gain Antena & $\geq 3 \mathrm{~dB}$ \\
\hline Return Loss & $\leq-10 \mathrm{~dB}$ \\
\hline Pola Radiasi & Bidirectional \\
\hline
\end{tabular}

Perancangan sistem antena akan dirancang dengan nilai return loss $\leq-10 \mathrm{~dB}$ pada frekuensi tengah UHF $586 \mathrm{MHz}$. Bandwidth televisi digital yaitu $216 \mathrm{MHz}$ yaitu dari rentang frekuensi

$$
\text { ELKOMIKA - } 21
$$


478 - 694 MHz. Spesifikasi tersebut digunakan untuk perancangan antena mikrostrip fraktal Köch sehingga bisa digunakan pada antena televisi digital.

\subsection{Perancangan Antena}

Perancangan antena mikrostrip mencakup penentuan desain patch berupa fraktal Köch iterasi-1, ground plane dengan teknik slot fraktal Köch iterasi-2, substrat, dan catuan berupa proximity coupled feed yaitu dengan menggunakan dua lapisan substrat dan feed line diletakkan diantara kedua substrat. Nilai frekuensi tengah yang diharapkan adalah $586 \mathrm{MHz}$ yang merupakan frekuensi tengah pada rentang frekuensi antena televisi digital. Parameter nilai dimensi perancangan antena dapat dilihat pada Tabel 3.

Tabel 3. Parameter Nilai Dimensi Antena

\begin{tabular}{|c|c|c|}
\hline Parameter & Simbol & Nilai \\
\hline Frekuensi Tengah & $f_{r}$ & $586 \mathrm{MHz}$ \\
\hline Cepat Rambat Gelombang di Udara & $c$ & $3 \times 10^{8} \mathrm{~m} / \mathrm{s}$ \\
\hline Konstanta Dielektrik Substrat & $\varepsilon_{r}$ & 4,6 \\
\hline Tebal Substrat & $h$ & $1,6 \mathrm{~mm}$ \\
\hline
\end{tabular}

Adapun dimensi antena hasil perhitungan yang akan dijadikan patokan simulasi adalah pada Tabel 4.

Tabel 4. Dimensi Antena Mikrostrip Fraktal Köch Hasil Perhitungan

\begin{tabular}{|c|c|c|}
\hline Dimensi Antena Mikrostrip & Parameter & Nilai \\
\hline Sisi Patch & $W_{p}$ & $128 \mathrm{~mm}$ \\
\hline Tinggi Sisi Fraktal Köch Iterasi-2 & $t$ & $12,31 \mathrm{~mm}$ \\
\hline Panjang Sisi Fraktal Köch Iterasi-2 & $a$ & $14,22 \mathrm{~mm}$ \\
\hline Panjang Gelombang & $\lambda$ & $511,94 \mathrm{~mm}$ \\
\hline Lebar Substrat & $W_{s}$ & $137,6 \mathrm{~mm}$ \\
\hline Panjang Substrat & $L_{s}$ & $137,6 \mathrm{~mm}$ \\
\hline Lebar Feed & $W_{f}$ & $2,96 \mathrm{~mm}$ \\
\hline Panjang Feed & $L_{f}$ & $65,217 \mathrm{~mm}$ \\
\hline Tebal Ground Plane & $k$ & $0,035 \mathrm{~mm}$ \\
\hline
\end{tabular}

\subsection{Antena Hasil Optimasi}

Optimasi antena dengan memperkecil ukuran patch dan ukuran feed sehingga bandwidth antena lebih besar dari sebelum optimasi dan return loss semakin bagus. Selanjutnya ukuran slot fraktal Köch pada ground plane diperbesar dari ukuran sebelum optimasi untuk mendapatkan nilai frekuensi pada rentang bandwidth antena mikrostrip fraktal Köch. Parameter antena setelah optimasi ditunjukkan pada Tabel 5.

Tabel 5. Dimensi Antena Mikrostrip Fraktal Köch Setelah Optimasi

\begin{tabular}{|c|c|c|}
\hline Dimensi Antena Mikrostrip & Parameter & Nilai \\
\hline Sisi Patch & $W_{p}$ & $65 \mathrm{~mm}$ \\
\hline Tinggi Sisi Fraktal Köch Iterasi-2 & $t$ & $24 \mathrm{~mm}$ \\
\hline Panjang Sisi Fraktal Köch Iterasi-2 & $a$ & $24 \mathrm{~mm}$ \\
\hline Panjang Gelombang & $\lambda$ & $511,94 \mathrm{~mm}$ \\
\hline Lebar Substrat & $W_{s}$ & $173,33 \mathrm{~mm}$ \\
\hline Panjang Substrat & $L_{s}$ & $173,33 \mathrm{~mm}$ \\
\hline Lebar Feed & $W_{f}$ & $1,5 \mathrm{~mm}$ \\
\hline Panjang Feed & $L_{f}$ & $65 \mathrm{~mm}$ \\
\hline Tebal Ground Plane & $k$ & $0,035 \mathrm{~mm}$ \\
\hline
\end{tabular}

ELKOMIKA - 22 
Adapun Grafik hasil return loss dan gain sebelum dan setelah dioptimasi ditunjukkan pada Gambar 2. Pola radiasi sebelum dan sesudah optimasi sama-sama bidirectional ditunjukkan pada Gambar 3.

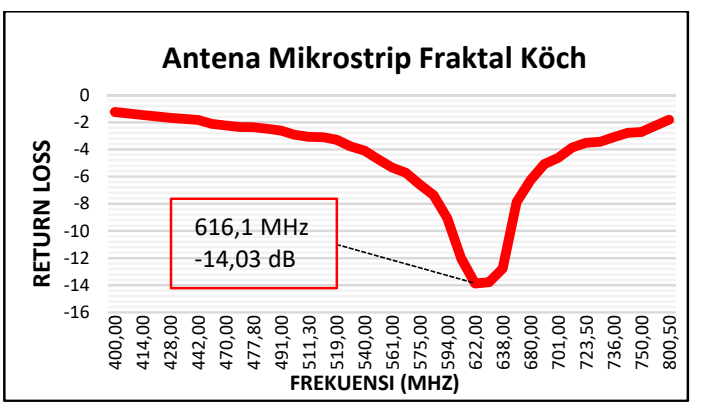

(a)

Gambar 2. Grafik Nilai Return Loss

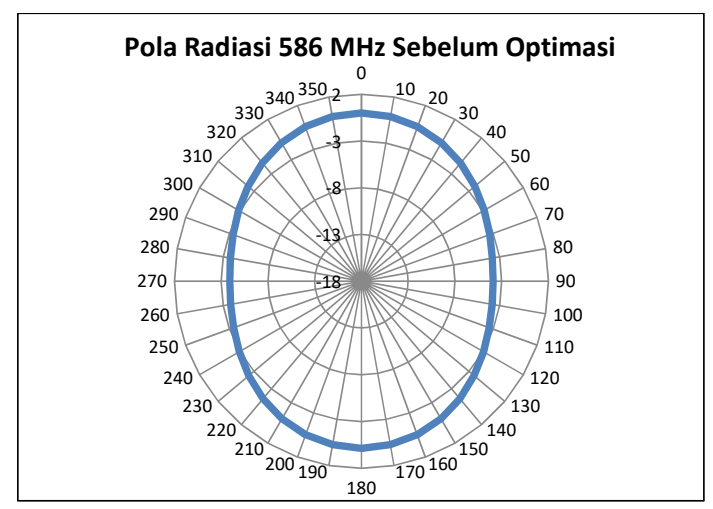

(a)

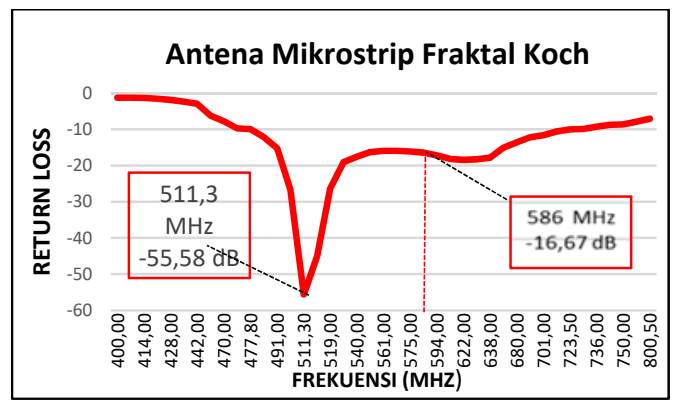

(b)

(a) Sebelum Optimasi (b) Setelah Optimasi

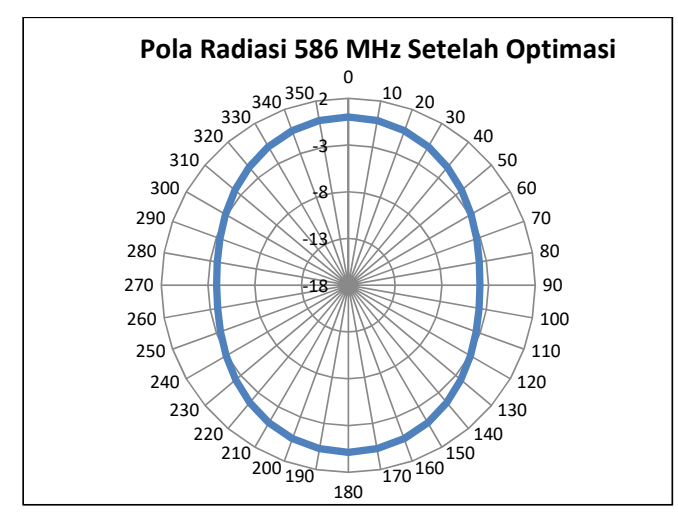

(b)

Gambar 3. Bentuk Pola Radiasi Antena (a) Sebelum Optimasi (b) Setelah Optimasi

Berdasarkan Gambar 2, nilai return loss sebelum optimasi didapatkan sebesar $-14,03 \mathrm{~dB}$. Setelah dilakukan optimasi, nilai return loss didapatkan lebih bagus yaitu sebesar $-16,67 \mathrm{~dB}$ pada frekuensi $586 \mathrm{MHz}$. Bandwidth antena sebelum optimasi belum memenuhi spesifikasi yaitu sebesar $53.16 \mathrm{MHz}$ pada rentang frekuensi $599.35-652.51 \mathrm{MHz}$. Setelah optimasi, didapatkan bandwidth yang sudah memenuhi spesifikasi sebesar 245,99 $\mathrm{MHz}$ yaitu dari rentang frekuensi 477,81 - 723,8 MHz. Gain antena sebelum optimasi 1,194 dB, setelah dioptimasi didapatkan gain yang memenuhi spesifikasi yaitu sebesar 3,085 dB pada frekuensi $586 \mathrm{MHz}$. Pada Gambar 3 dapat dilihat bahwa bentuk pola radiasi antena sebelum dan setelah optimasi memiliki bentuk yang sama yaitu bidirectionalyang berarti pola pemancaran gelombang elektromagnetik antena pada dua arah tertentu. Tidak ada perbedaan yang signifikan dari bentuk pola radiasi antena pada saat sebelum dan sesudah dilakukan optimasi, karena optimasi antena hanya dilakukan untuk menggeser nilai frekuensi kerja antena agar memenuhi spesifikasi sistem. Setelah hasil optimasi antena memenuhi spesifikasi maka selanjutnya dilakukan pembuatan antena.

\subsection{Realisasi Antena}

Setelah dilakukan simulasi menggunakan software perancang antena, antena direalisasikan berdasarkan hasil simulasi yang mendekati spesifikasi yang mampu mendukung penggunaan 
sistem televisi digital. Dimensi hasil realisasi antena sebesar 17,33 x 17,33 cm. Adapun bentuk antena mikrostrip hasil realisasi ditunjukkan pada Gambar 4.

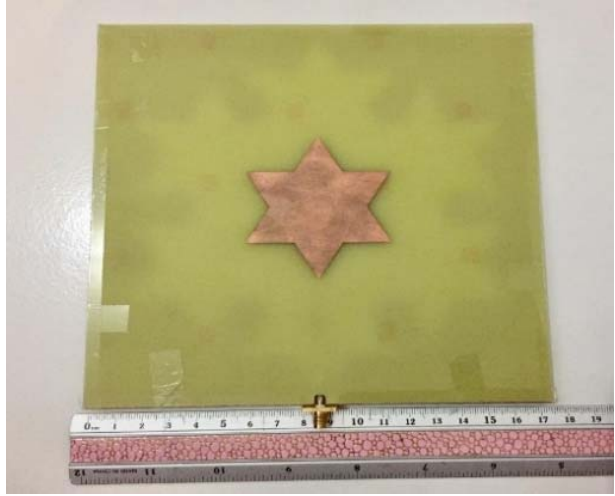

(a)

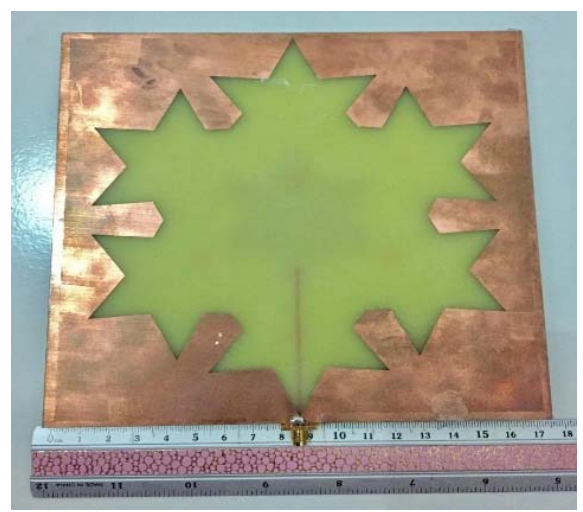

(b)

Gambar 4. Hasil Realisasi Antena Mikrostrip Fraktal Köch (a) Tampak Depan (b) Tampak Belakang

Realisasi ini dilakukan dengan mengkonversi desain antena pada software menjadi format gambar. Fabrikasi dilakukan dengan menggunakan bahan substrat FR-4 Epoxy dengan konstanta dielektrik bernilai 4,6 dan ketebalan substrat 1,6 mm. Patch yang direalisasikan berbentuk fraktal Köch iterasi-1 dan ground plane berupa fraktal Köch iterasi-2 Patch dan ground plane menggunakan bahan tembaga dengan ketebalan 0,035 mm. Setelah dilakukan fabrikasi, antena mikrostrip dipasang port pada catuannya dengan impedansi karakteristik sebesar 50 ohm. Bahan yang digunakan adalah timah yang disolder pada feed antena mikrostrip. Setelah itu, dilakukan pengukuran pada antena mikrostrip untuk melihat hasil parameter setelah realisasi.

\section{PENGUKURAN DAN ANALISIS}

\subsection{Pengukuran Bandwidth dan Return Loss}

Pengukuran bandwidth dan return loss ini bertujuan untuk membandingkan hasil yang didapat pada simulasi antena. Pengukuran dilakukan di perangkat Network Analzyer T280A pada rentang frekuensi ukur perangkat $300 \mathrm{kHz}-8 \mathrm{GHz}$. Hasil pengukuran bandwidth dan return loss ditunjukkan pada Gambar 5. Pengukuran Return Loss dilihat dengan tanda marker 1 pada frekuensi $586 \mathrm{MHz}$. Nilai return loss yang didapat adalah -13,71 dan nilai bandwidth adalah $216 \mathrm{MHz}$ yaitu dari frekuensi $478-694 \mathrm{MHz}$.

Berdasarkan hasil pengukuran, nilai bandwidth menunjukkan hasil yang lebih rendah daripada hasil simulasi. Begitu juga nilai return loss mengalami penurunan setelah dilakukan pengukuran sebesar $-13,71 \mathrm{~dB}$. Perbedaan hasil ini disebabkan oleh faktor seperti ukuran dimensi fabrikasi yang memungkinkan kurang pas dibandingkan hasil simulasi dan ketelitian feed yang berbentuk proximity coupled juga mempengaruhi saat fabrikasi. 


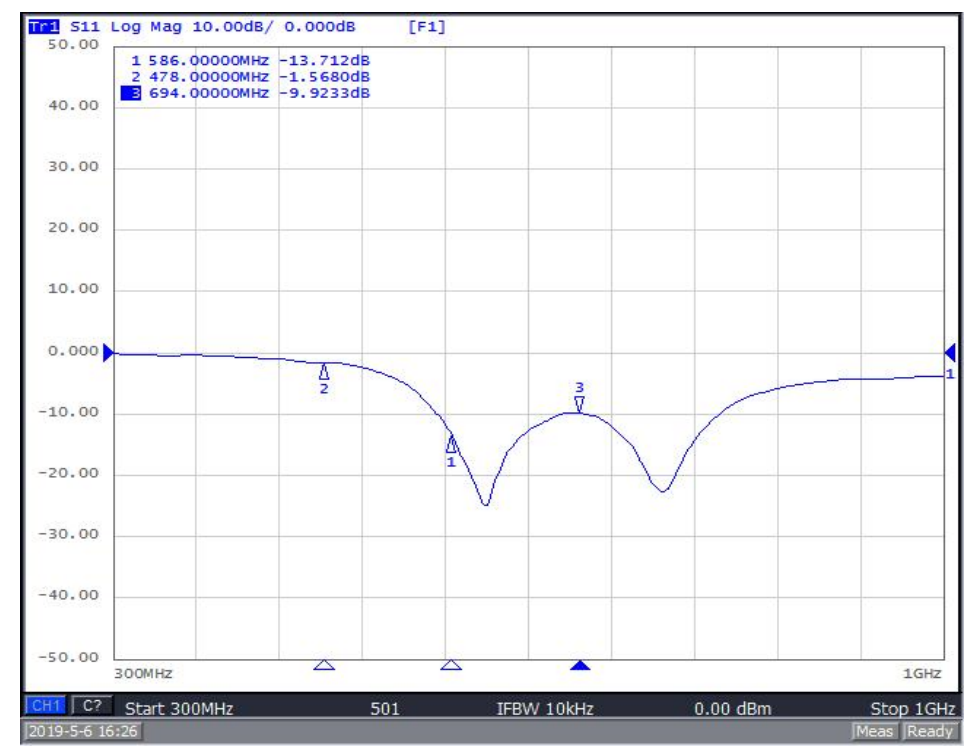

Gambar 5. Hasil Pengukuran Bandwidth dan Return Loss

Selain itu juga dipengaruhi oleh faktor ketelitian proses pensolderan catuan antena dan alat ukur yang memiliki performansiyang kurang baik terutama pada konektor alat ukur ke antena yang menyebabkan pergerakan grafik hasil pengukuran naik turun tidak stabil. Sehingga menyebabkan nilai bandwidth dan return loss turun dibandingkan hasil simulasi.

\subsection{Pengukuran Pola Radiasi}

Pola radiasi diukur dengan cara pengunaan dua antena identik, yaitu dua antena yang memiliki spesifikasi yang sama. Hasil pengukuran pola radiasi yang didapatkan berdasarkan pengukuran dibandingkan dengan hasil pada tahap simulasi yang diolah di Microsoft Excel ditunjukkan pada Gambar 6.

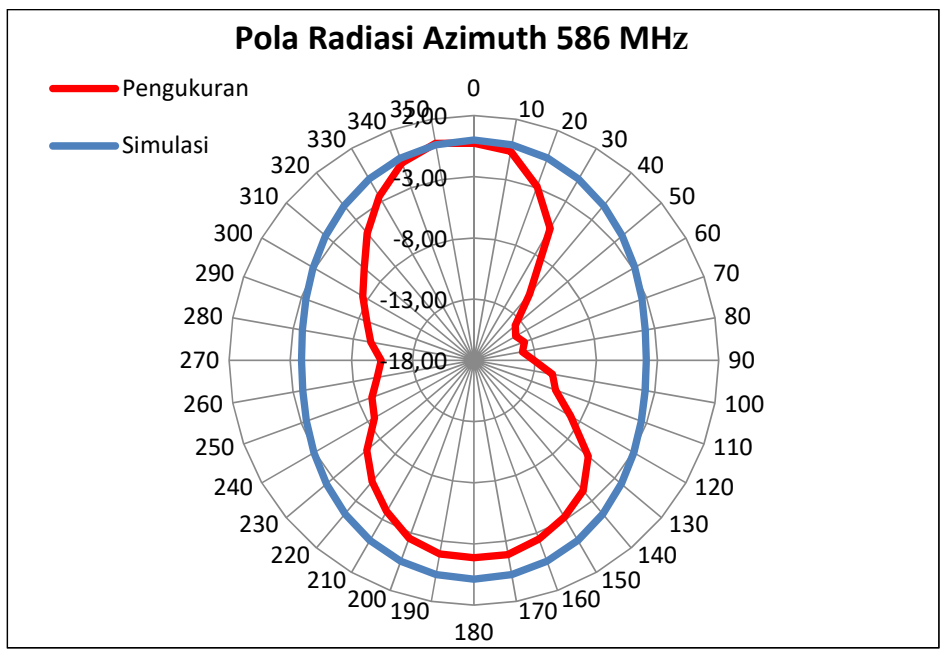

Gambar 6. Perbandingan Pola Radiasi Hasil Simulasi dengan Pengukuran pada frekuensi $586 \mathrm{MHz}$ 
Berdasarkan Gambar 6, bentuk pola radiasi hasil simulasi dan pengukuran antena adalah sama yaitu bidirectional.

\subsection{Pengukuran Polarisasi}

Adapun grafik perbandingan polarisasi hasil perhitungan dengan hasil simulasi yang diolah di Microsoft Exce/ ditunjukan pada Gambar 7 dan Gambar 8.

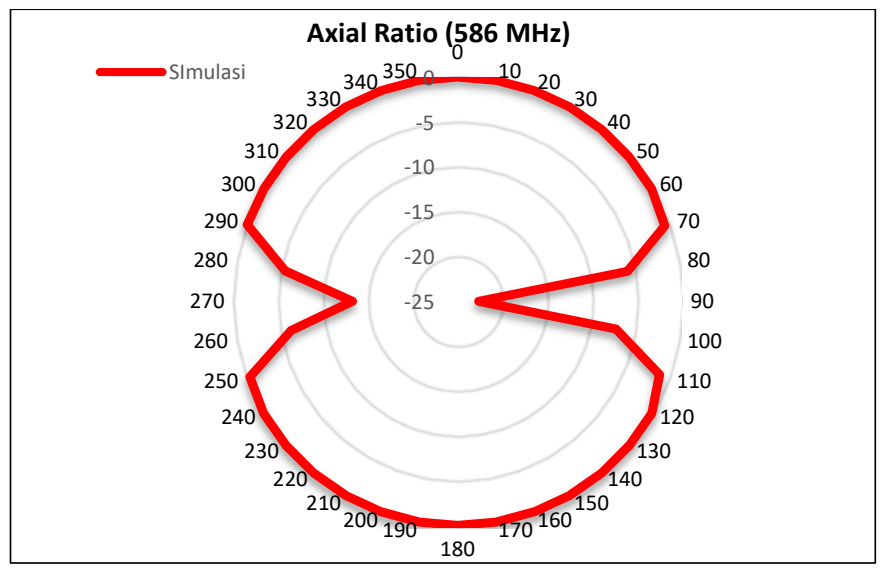

\section{Gambar 7. Axial Ratio Hasil Simulasi pada Frekuensi 586 MHz}

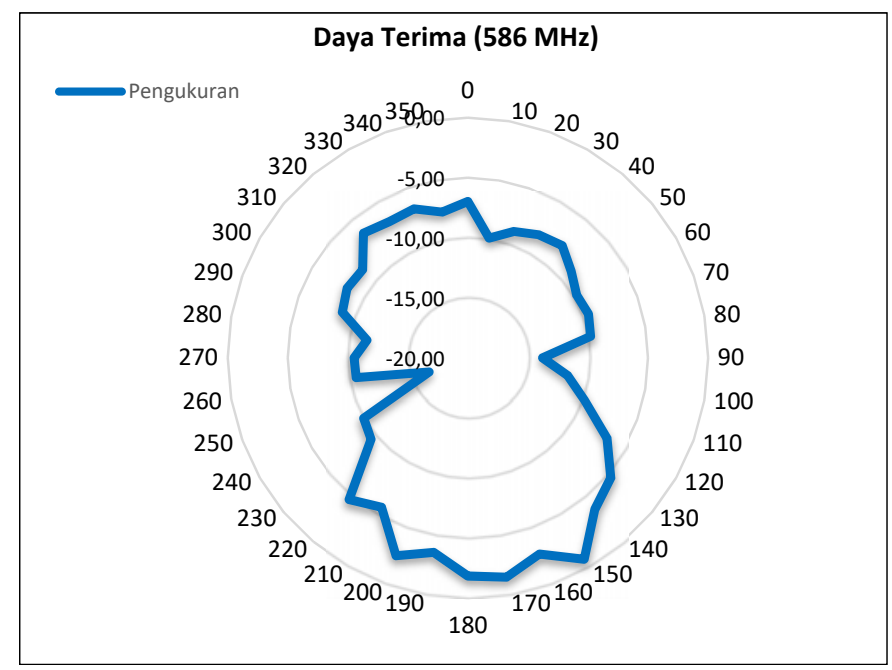

\section{Gambar 8. Daya Terima Hasil Pengukuran pada Frekuensi 586 MHz}

Gambar 8 menunjukkan daya terima untuk menentukan nilai Axial Ratio hasil pengukuran. Nilai $P_{\text {watt mayor }}$ didapatkan sebesar $-33,35 \mathrm{~dB}$ dan $P_{\text {watt minor }}$ sebesar $-49.71 \mathrm{~dB}$. Maka, didapatkan nilai axial ratio sebesar $1,514 \mathrm{~dB}$ pada frekuensi $586 \mathrm{MHz}$. Hal ini berarti polarisasi pada frekuensi ini berjenis sirkular. Berdasarkan Gambar 7 dan Gambar 8, terdapat perbedaan jenis polarisasi hasil pengukuran dibandingkan dengan simulasi. Polarisasi pada simulasi menunjukkan jenis polarisasi linier sedangkan hasil pengukuran realisasi antena poarisasi berbentuk sirkular. Perubahan ini terjadi karena proses pengukuran yang berpengaruh pada keadaan antena hasil fabrikasi, ketidaktelitian proses pensolderan sampai keakuratan proses pengukuran yang masih jauh disebabkan keadaan alat yang digunakan, sehingga ikut mempengaruhi hasil pengukuran dibandingkan hasil simulasi. 


\subsection{Pengukuran Gain}

Pengukuran gain dilakukan dengan menggunakan metode antena identik yaitu satu antena digunakan sebagai pemancar $\left(T_{x}\right)$ dan satu antena digunakan sebagai penerima $\left(R_{x}\right)$ dengan cara yang sama pada pengukuran pola radiasi bedanya antena tetap dibiarkan tetap saling berhadapan tanpa perlu memutar AUT receiver dan tiang AUT receiver. Hasil pengukuran gain adalah sebesar 1,642 dB pada frekuensi $586 \mathrm{MHz}$. Hal ini dapat dilihat bahwa nilai gain hasil perhitungan lebih kecil dibandingkan hasil simulasi. Hal ini disebabkan kualitas fabrikasi dan proses penyolderan feed antena yang tidak dapat mempertahankan performansi seperti pada simulasi. Sehingga gain antena mengalami penurunan setelah dilakukan fabrikasi. Adapun perbandingan hasil simulasi dan pengukuran dapat dilihat pada Tabel 6 berikut.

Tabel 6. Perbandingan Hasil Simulasi dan Pengukuran

\begin{tabular}{|c|c|c|}
\hline Parameter & Simulasi & Pengukuran \\
\hline Frekuensi $(\mathrm{RL}<-10 \mathrm{~dB})(\mathrm{MHz})$ & $477,81-723,8$ & $478-694$ \\
\hline Return Loss $586 \mathrm{MHz}(\mathrm{dB})$ & $-16,67$ & $-13,71$ \\
\hline Bandwidth $(\mathrm{MHz})$ & 245,99 & 216 \\
\hline Gain $(\mathrm{dB})$ & 3,085 & 1,642 \\
\hline Pola Radiasi & Bidirectional & Bidirectional \\
\hline Polarisasi & Linier & Sirkular \\
\hline
\end{tabular}

\subsection{Implementasi ke TV}

Antena diujikan dalam 3 kondisi yaitu kondisi pada TV dengan antena lain, tanpa antena, dan menggunakan antena mikrostrip fraktal Köch. Keadaan televisi tanpa antena ditunjukkan pada Gambar 9. Keadaan TV tanpa antena menunjukkan gambar hitam putih sebelum diberi antena. Dan hasilnya tidak ada gambar yang dihasilkan dalam keadaan tanpa antena.

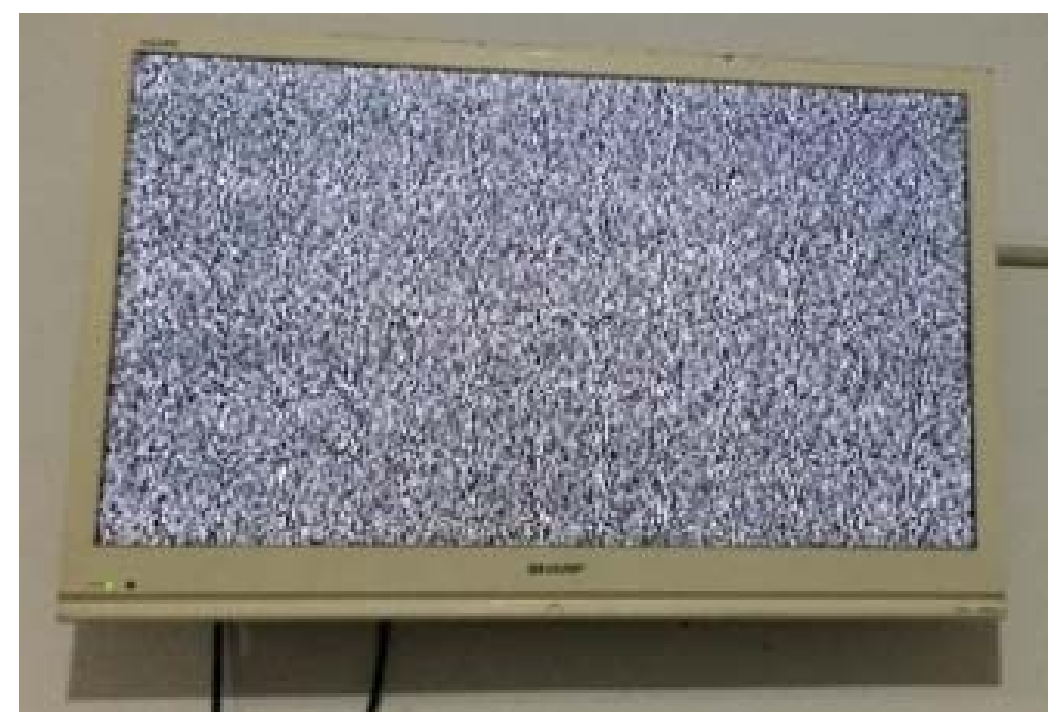

Gambar 9. Keadaan TV Tanpa Antena 


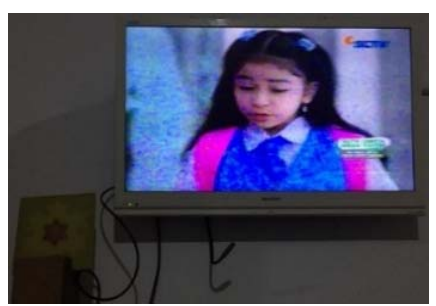

(a) SCTV-Uji

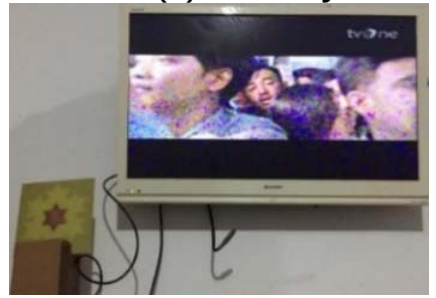

(c) TvOne-Uji

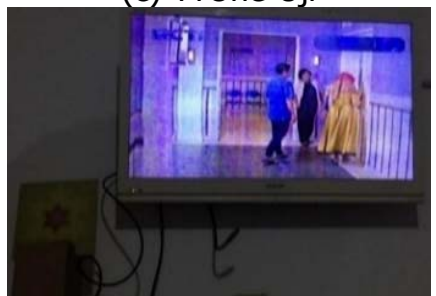

(e) RCTI-Uji

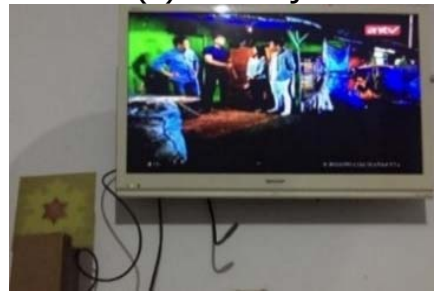

(g) antv-Uji

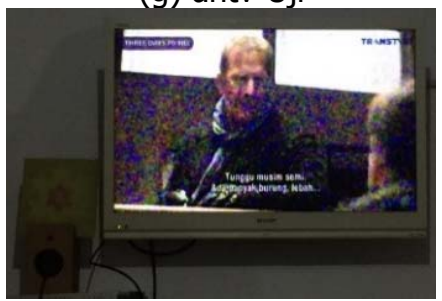

(i) TRANSTV-Uji

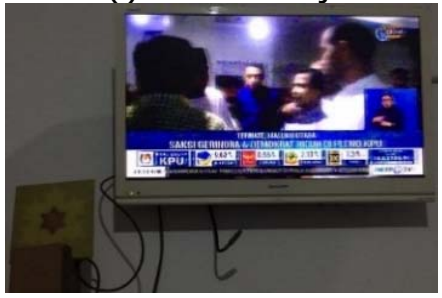

(k) METROTV-Uji

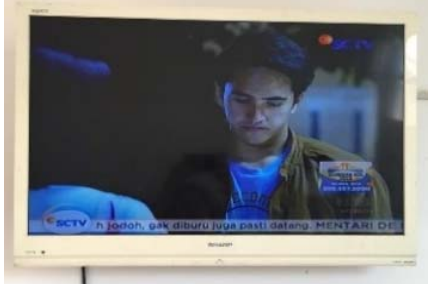

(b) SCTV-Pembanding

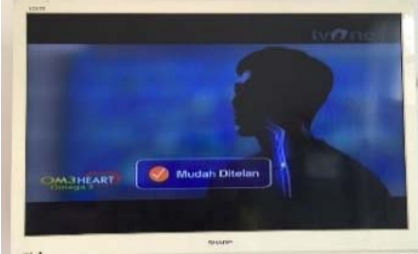

(d) TvOne-Pembanding

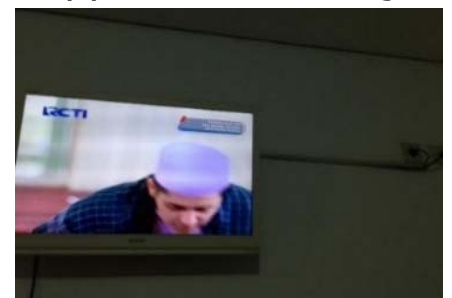

(f) RCTI-Pembanding

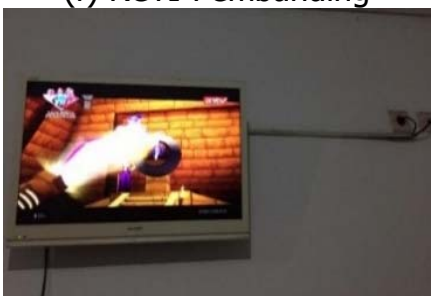

(h) antv-Pembanding

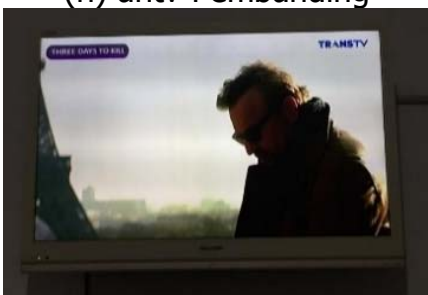

(j) TRANSTV-Pembanding

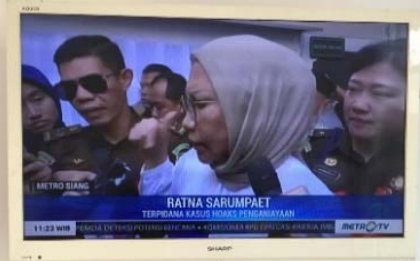

(I) METROTV-Pembanding

Gambar 10. Keadaan Gambar Implementasi Antena Mikrostrip Fraktal Köch dengan Antena Existing 
Antena mikrostrip fraktal Köch hasil perancangan dimplementasikan di dalam ruangan pada TV digital kemudian gambar yang dihasilkan dibandingkan dengan saat TV menggunakan antena Yagi, yaitu antena TV existing. Hasil implementasi antena mikrostrip fraktal Köch dengan antena existing ditunjukkan pada Gambar 10. Berdasarkan hasil implementasi, keadaan gambar siaran televisi menggunakan antena mikrostrip fraktal Köch masih dapat dilihat dengan baik meskipun kurang jernih dibandingkan dengan menggunakan antena TV existing. Hal ini disebabkan ketidaktelitian proses realisasi antena pada saat fabrikasi yang menyebabkan turunnya nilai gain sehingga berpengaruh pada tingkat kejernihan gambar siaran televisi yang dihasilkan. Meskipun demikian, antena mikrostrip fraktal Köch hasil realisasi masih dapat menjangkau siaran TV karena sudah bekerja pada frekuensi TV digital (478 MHz - 694 MHz) meskipun gain antena mengalami penurunan.

\section{KESIMPULAN}

Berdasarkan pengujian dan analisis yang telah dilakukan sebelumnya maka dapat dibuat kesimpulan sebagai berikut:

1. Teknik fraktal Köch dengan proximity coupled feed dapat memperbesar bandwidth pada antena mikrostrip. Hasil simulasi menghasilkan bandwidth sebesar 245,99 MHz dan hasil pengukuran menghasilkan bandwidth sebesar $216 \mathrm{MHz}$ sehingga bisa menjangkau rentang frekuensi televisi digital yang sesuai spesifikasi.

2. Pengukuran realisasi antena menunjukkan hasil yang mengalami penurunan dari hasil simulasi yang ditunjukkan pada penurunan nilai return loss dan gain. Hasil simulasi menghasilkan return loss sebesar $-16,67 \mathrm{~dB}$ sedangkan hasil pengukuran sebesar $13,71 \mathrm{~dB}$ pada frekuensi $586 \mathrm{MHz}$. Nilai gain hasil simulasi sebesar 3,085 dB mengalami penurunan menjadi $1,642 \mathrm{~dB}$ setelah direalisasian.

3. Antena mikrostrip fraktal Köch yang dirancang mampu diaplikasikan dalam menangkap siaran televisi digital dan menghasilkan kualitas gambar yang sama baik dengan kualitas antena lain sebagai pembanding. Adanya penurunan tingkat kejernihan gambar pada siaran TV digital menggunakan antena yang dirancang dispengaruhi oleh faktor penurunan gain antena pada proses fabrikasi.

\section{DAFTAR RUJUKAN}

Alaydrus, M. (2011). Antena Prinsip dan Aplikasi. Yogyakarta: Graha Ilmu.

Candra, H. (2013). Desain Antena Kubikal 600 MHz sebagai Antena Penerima Siaran Televisi

Indoor/Outdoor. Universitas Trisakti: Penelitian Kemitraan YPPTI.

Denny, S. (2010). Alokasi Frekuensi Kebijakan dan Perancangan Spektrum Indonesia. Jakarta: Direktorat Jenderal Pos dan Telekomunikasi.

Gultom, A. D. (2018). Digitalisasi Penyiaran Televisi di Indonesia. Buletin Pos dan Telekomunikasi, 16(2), 91-100.

Ismahayati, A., Soh, P. J., Hadibah, R., \& Vandenbosch, G. (2011). Design and Analysis of a Multiband Koch Fractal Monopole Antena. 2011 IEEE International RF \& Microwave Conference (hal. 58-62). Seremban, Negeri Sembilan: IEEE.

Menkominfo. (2011). Peraturan Kominfo No. 23/PER/M.KOMINFO/11/2011. Dalam Rencana Induk (masterplan) Frekuensi Radio untuk Keperluan Televisi Siaran Digital Terestrial Pada Pita Frekuensi Radio 478 - 694 MHz (hal. 1-10). Jakarta: Kominfo.

$$
\text { ELKOMIKA - } 29
$$


Menkominfo. (2012). Peraturan Kominfo No. 05/PER/M.KOMINFO/02/2012. Standar Penyiaran Televisi Digital Terestrial Penerimaan Tetap Tidak Berbayar (Free-to-Air), (Vol. 1-3).

Nugroho, H. A. (2014). Perancangan dan Realisasi Antena Mikrostrip Berbentuk Fraktal Koch. Bandung: Telkom University.

Wahyu, Y., Syakirotunnikmah, U., \& Wijanto, H. (2015). Antena Fraktal Koch dengan Catuan Emc pada UHF untuk Aplikasi Televisi Digital Terestrial. Elkomika, 15(1), 1-5. 